\title{
Alcohol consumption and hazardous drinking in western Kenya-a household survey in a health and demographic surveillance site
}

Rachel Jenkins ${ }^{1 *}$, Caleb Othieno ${ }^{2}$, Linnet Ongeri ${ }^{3}$, David Kiima ${ }^{4}$, Peter Sifuna ${ }^{5}$, James Kingora ${ }^{6}$, Raymond Omollo ${ }^{3}$ and Bernhards Ogutu ${ }^{3}$

\begin{abstract}
Background: Alcohol use and hazardous drinking have been studied in school children and in urban areas of Kenya, but there has been no adult survey of these issues in a rural household population.

Methods: This study reports the prevalence of alcohol consumption and hazardous drinking in a household survey of a demographic surveillance site in rural Kenya. Information collected included demographic characteristics, socio-economic factors, recent life events and perceived social support. Alcohol consumption was assessed by questions about quantity and frequency. The Alcohol Use Disorders Identification Test (AUDIT) measured hazardous alcohol use. The Clinical Interview Schedule- Revised assessed common mental disorder, and the Psychosis Screening Questionnaire indicated the presence of psychotic symptoms.

Results: The study found that lifetime and current alcohol consumption were $10.8 \%$ and $9.2 \%$ respectively. Current alcohol consumption was significantly higher in men (OR 0.4, $p<0.001$ for women) and in the self-employed (OR 1.8, $p=0.013$ ), after adjustment for factors significant at the bivariate level.

Hazardous drinking was significantly higher in men (OR 0.3, $p<0.001$ for women), people living in larger households (OR 1.8, $p=0.021$ ), people who were single (OR 1.7, $p=0.093)$, and in those who are self-employed $(\mathrm{OR} 1.8, p=0.036)$, after adjustment for factors significant at the bivariate level.

Conclusion: This study suggests that alcohol consumption and hazardous drinking in the general population in a poor rural area in Nyanza Province is still relatively low. This represents an important public health educational opportunity to keep such rates low before increasing income and employment opportunities enable higher access to alcohol and other substances, and before the higher consumption found by studies on urban youth, especially neighbouring Kisumu town, spreads to the rural areas.
\end{abstract}

\section{Background}

Alcohol represents a significant public health hazard for Africa as marketing strategies of alcohol focus increasingly on efforts to exploit the African market, and as incomes gradually increase [1]. Alcohol consumption is responsible for $4 \%$ of global disability-adjusted life years [2,3]. Alcohol use is thought to be a causal factor in 60 types of diseases and injury, a contributory factor in 200 other diseases as well as being associated with violence, suicide, child abuse and sickness absence from

\footnotetext{
* Correspondence: Rachel@olan.org

${ }^{1}$ Health Services and Population Research Department, Institute of Psychiatry, Kings College London, de Crespigny Park, London SE 5 8AF, UK

Full list of author information is available at the end of the article
}

work $[4,5]$. Hazardous alcohol use particularly impacts on physical and mental health outcomes, and is associated with economic disadvantage in both resource-rich $[6,7]$ and resource-poor $[8,9]$ countries. While there continues to be debate about whether light alcohol consumption is cardio-protective in western countries [10-13], such an effect was not found in two Indian studies [14, 15].

In sub-Saharan Africa, evidence indicates that alcohol consumption is increasing in many developing countries within the region [16, 17]. In much of Africa estimates of alcohol consumption rely on volume of sales which is misleading, because the industry is poorly regulated, and there are many illicit and counterfeit products, as evidenced for example by recent reports from Kenya [18]. 
The main determinants of alcohol related harm are volume of alcohol consumed and pattern of consumption [19]. Therefore, in order to inform public health prevention strategies, it is important to study risk factors for overall alcohol use as well as hazardous drinking. Despite the Western evidence on the contribution of alcohol consumption and hazardous drinking to morbidity and mortality, there is a dearth of epidemiological studies in low and middle income countries. In Kenya, there have been epidemiological studies of harmful use of alcohol in adults attending medical facilities [20], schools [21], and small scale surveys [22, 23]. There has also been a larger scale survey examining prevalence of alcohol use with sociodemographic factors including poverty, marital status, sex and age in western Kenya [24]. However there has been no household survey examining the relationship of alcohol use and hazardous drinking with not only sociodemographic factors but also psychosocial factors. Furthermore the Lo et al. study examined prevalence of getting drunk in the last month but did not use a specific tool to assess hazardous drinking [24]. This paper therefore used the opportunity of a wider epidemiological survey of psychiatric morbidity in a demographic surveillance site in rural Kenya to examine the prevalence of alcohol use and hazardous drinking, and their associated socio-demographic and psychosocial risk factors.

The area of the demographic surveillance site [25] is largely rural, with most residents living in villages, which are a loose conglomeration of family compounds near a garden plot and grazing land. The majority of the houses are mud-walled with either grass thatched or corrugated iron-sheet roofs. Water is sourced mainly from community wells, local streams and the lake for those living on the shores of Lake Victoria. Most water sources are not chlorinated. Subsistence farming, animal husbandry and fishing are the main economic activities in the area.

\section{Methods}

Data for this analysis were drawn from a wider epidemiological household survey of psychiatric morbidity, immunity and malaria in a demographic surveillance site in rural Kenya to examine the prevalence of alcohol use and hazardous drinking, and their associated sociodemographic and psychosocial risk factors. The data for this study was collected between December 2012 and June 2013.

\section{Study population}

The sample frame is a subdistrict in Kenya, in an area endemic for malaria, namely Maseno area within Kisumu County, Nyanza Province, Western Kenya which has a population of 70,805 [15]. Females constitute $53 \%$ of the population. The mean household number is 4 people per household with a population density of about 374 people $/ \mathrm{km}^{2}$. The population is largely young with a mean age of 23 years. The population $0-14$ years constitutes $46 \%$, ages $15-64$ years constitute $49 \%$ and ages $65+$ years constitute $5 \%$.

The population is primarily rural black African, and the languages spoken are Luo (predominant ethnic group), Kiswahili and English (Fig. 1).

The study sample was selected from Maseno Area within Kisumu County, western Kenya. Maseno Area is subdivided into 4 locations, 17 sub-locations and 184 enumeration areas (villages) based on mapping work done earlier by the Kombewa Health and Demographic Surveillance System (Kombewa HDSS) run by the KEMRI/Walter Reed Project. The Kombewa HDSS is a longitudinal population registration system set up to monitor the evolving health and demographic problems of the study population in Kombewa and Maseno areas [25]. Some villages with less than 50 households were merged together to create new enumeration areas, so that the final total of enumeration areas was 170. A random sample of 7 households was drawn from each enumeration area, to give a projected sample of 1190 households, and hence 1190 adults. Village maps were used to assign households and guide the research assistants during the survey. Using the Kish Grid Method, one individual was selected at random from each of the sampled households [26]. Thus only one individual per household was interviewed. A total of 1190 households were visited, and a total sample of 1147 participants agreed to be interviewed. The demographics and reasons for the refusal were recorded in notebooks by the research assistants.

\section{Study procedures}

Meetings were held with community leaders to explain the purpose of the study and to answer questions. The participants in the survey were approached for informed consent, and then received a structured epidemiological assessment using the Clinical Interview Schedule -Revised, of mental disorders, accompanied by additional sections on socio-demographic data, life events, social networks, social supports, disability/activities of daily living, quality of life, use of health services, alcohol and substance abuse, adapted from the UK adult psychiatric morbidity schedule [27].

The interview was administered by one of a group of 20 research assistants using a PDA, on which the interview questions were programmed and responses were recorded. The research assistants received a 5 day training course, and were supervised in the field by a field manager. The survey was administered in either English or Swahili or Luo, depending on which language the participant found easiest. The research assistants were fluent in all three languages, and the questions were available on the PDA in all three languages. The research assistants all 


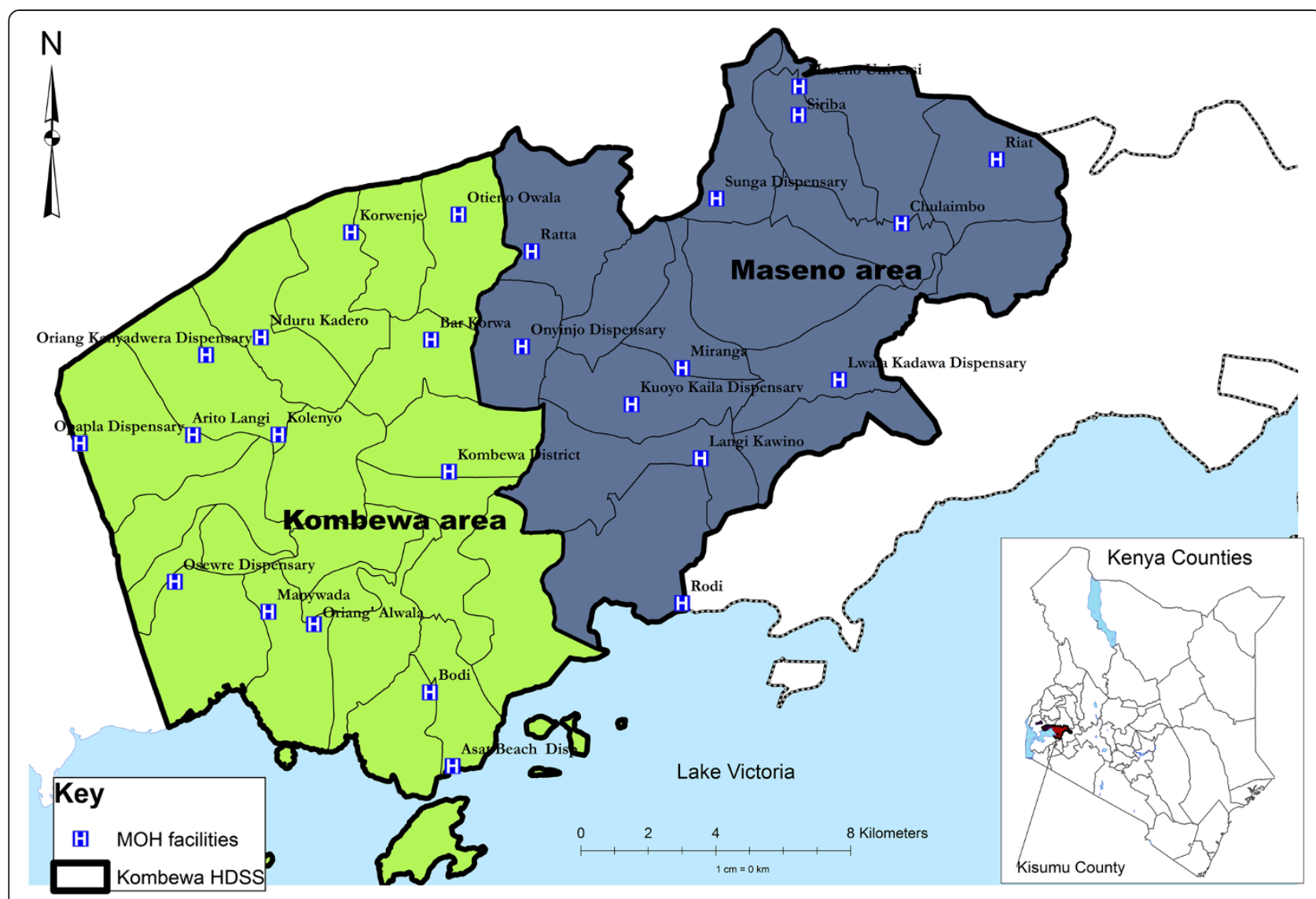

Fig. 1 Location of study site

came from the local community, so had knowledge of the community and the social norms. Each session took between 1 and $2 \mathrm{~h}$ depending on the level of morbidity. The interviews were conducted in a secluded section of the respondent's home if privacy was possible, or else in a quiet place outside the home which was well out of earshot of other people.

Information collected included demographic characteristics, socio-economic factors, recent life events and perceived social support. The Clinical Interview ScheduleRevised (CIS-R) [28], assessed common mental disorder (CMD), and the Alcohol Use Disorders Identification Test (AUDIT) [29], measured hazardous alcohol use.

Demographic information collected included sex, age, marital status, ethnicity, and household status (head, spouse or other). Socio-economic factors included employment status, income, education attainment, and housing variables. We did not collect data on religious affiliation.

Current alcohol use was determined by a positive response to the question:"Do you ever drink alcohol nowadays, including drinks you brew or make at home?" Lifetime non-drinkers (abstainers) were those who answered yes to 'Have you always been a non-drinker'. The category of lifetime drinkers included were those who had not always been a non-drinker and current drinkers.

The AUDIT is a cross-culturally validated instrument for assessment of alcohol misuse in the general population. The ten- item instrument includes questions to determine patterns of drinking considered harmful, hazardous and symptomatic of dependence in the preceding 12 months [29].

The CIS-R [28] is a gold standard instrument for use by lay interviewers in assessing common mental disorders in community settings, which has been widely used in low-income countries [30-32], including Kenya [33] and Tanzania [34, 35]. Scores are calculated from an average of four questions across 14 symptom types and taken together with algorithms based on the ICD-10 [36] provide six possible neurotic diagnoses including depressive episode (mild, moderate or severe), obsessive compulsive disorder, panic disorder, phobic disorder, generalised anxiety disorder and mixed anxiety/depressive disorder.

Respondents were given a list of 18 different stressful life events, and asked to say which, if any, they had experienced in the past six months. The list included relationship problems, employment, financial crises and victimisation 
experiences. The list was originally developed for the 1993 British psychiatric morbidity survey $[37,38]$ and tailored for the Tanzanian and Kenya contexts.

Perceived social support was assessed from respondents' answers to seven questions previously used for the 1992 Health Survey for England [39], and the British Surveys of Psychiatric Morbidity [40, 41]. Participants responded "true", "partly true" or "certainly true" in response to the question 'There are people I know who'; (i) Do things to make me happy; (ii) Who make me feel loved; (iii) Who can be relied on no matter what happens; (iv) Who would see that I am taken care of if I needed to be; (v) Who accept me just as I am; (vi) Who make me feel an important part of their lives; and (vii) Who give me support and encouragement.

Information on social networks was obtained through questions about the number of friends or relatives who informants felt close to including (i) Adults who lived with the respondent and to whom they felt close; (ii) Relatives living elsewhere to whom they felt close; and (iii) Friends or acquaintances living elsewhere who informants would describe as close or good friends. These questions were taken from psychiatric morbidity surveys conducted in Britain [42, 43].

Specific questions were also asked about caring responsibilities (Do you give care due to long term physical or mental disorder or disability? And if yes, time spent giving care in a week); about growing up with one natural parent or two until age 16; and about spending time in an institution before the age of 16 .

\section{Statistical analysis}

We examined the prevalence of alcohol consumption and calculated the prevalence of hazardous drinking. We also examined the predictors of current alcohol consumption and hazardous alcohol consumption. The bivariate analysis calculated odds ratios (with $95 \%$ confidence intervals) to quantify the level of association of each variable with current alcohol consumption and with hazardous alcohol use. We then conducted logistic regression to calculate adjusted odds ratios. Both bivariate analysis and adjusted analysis were conducted using STATA version 11.2 [44]. The level of statistical significance was set at $5 \%$. Logistic regression computes the relevant odds for each predictor or interaction term, takes the natural logarithm of the odds (computes the logit), conducts a linear regression analysis on the predicted values of the logit, and then takes the exponential function of the logit to compute the odds ratio. We assessed the goodness of fit as well as the model complexity using the Akaike's information criterion (AIC) and the final model we ended up with is the one that maximized AIC. We did not employ other model selection techniques as we assumed a linear model with errors normally distributed.
Households have been categorized into different socioeconomic levels using an index of household assets, constructed applying the principal component analysis procedure, as a proxy indicator for socio-economic status. In developing the asset quintiles, type of house, roofing \& walling material, source of water, toilet facility and land have been used $[45,46]$. Each question in the AUDIT is scored between zero and four with a score of eight and over considered indicative of hazardous use. A score of 12 or more across the 14 sections of the CIS-R was considered an indication of any CMD [28, 37, 38]. Life event scores were grouped into none, one, two, and three or more life events. Perceived social support scores were categorised into no, moderate or severe lack of social support. Social network scores were grouped into "none to three", "four to eight" and "nine or more".

\section{Ethics}

Ethical approval was granted by the Kings College London and Kenya Medical Research Institute Boards of Research Ethics respectively (PNM/11/12-54, SSC2374), and permission was obtained to conduct the study in households in Maseno area, which is part of the KEMRI/ WRP Kombewa HDSS. Consent to participate in the study was voluntary and was administered at individual level after receiving consent from the head of household. Head of household was defined as the father when he was there and if he was not there then it was the mother, and if neither were present it was the grandfather or grandmother. This was in keeping with the cultural norms in the area. Written and witnessed informed consent was asked of the participants to take part in the study.

\section{Results}

Table 1 gives the life time and current prevalence rates for alcohol consumption and hazardous drinking in men and women. $14.5 \%$ of men and $6.8 \%$ of women reported life time drinking, and slightly lower proportions reported current alcohol consumption (13.1\% of men and $4.8 \%$ of women). Hazardous drinking was reported by $9.5 \%$ of men and $2.9 \%$ of women.

Table 2 examines the sociodemographic, economic, social and psychological risk factors for current alcohol use.

Table 1 Life time and current prevalence rates for alcohol, tobacco and cannabis use in Maseno area, Kenya

\begin{tabular}{llll}
\hline & $\begin{array}{l}\text { Life time } \\
\text { alcohol }\end{array}$ & $\begin{array}{l}\text { Current alcohol } \\
\mathrm{N}(\%)\end{array}$ & $\begin{array}{l}\text { Hazardous drinking } \\
\mathrm{N}(\%)\end{array}$ \\
\hline Total Prevalence & $124(10.8)$ & $105(9.2)$ & $73(6.4)$ \\
Male prevalence & $87(14.5)$ & $79(13.1)$ & $57(9.5)$ \\
Female Prevalence & $37(6.8)$ & $26(4.8)$ & $16(2.9)$ \\
\hline
\end{tabular}


Table 2 Prevalence of current alcohol use and its relationship with socio demographic, economic, social variables and CMD, using bivariate analysis (odds ratios)

\begin{tabular}{|c|c|c|c|c|}
\hline Factors & & Prevalence: n (\%) & Unadjusted OR & $p$-value \\
\hline \multirow[t]{2}{*}{ Sex } & Male & $79(13.1)$ & 1 & - \\
\hline & Female & $26(4.8)$ & 0.3 (0.21 to 0.53$)$ & $<0.001$ \\
\hline \multirow[t]{3}{*}{ Age group } & $<30$ years & $32(11.4)$ & 1 & - \\
\hline & $30-60$ years & $44(9.8)$ & $0.8(0.52$ to 1.37$)$ & 0.495 \\
\hline & $>60$ years & $11(6.4)$ & 0.5 (0.26 to 1.09$)$ & 0.086 \\
\hline \multirow[t]{2}{*}{ Household size } & $<=6$ people & $47(8.3)$ & 1 & - \\
\hline & $>6$ people & $58(10.0)$ & 1.5 (0.97 to 2.18$)$ & 0.068 \\
\hline \multirow[t]{3}{*}{ Marital Status } & Married/cohabiting & $66(9.2)$ & 1 & - \\
\hline & Single & $22(12.0)$ & 1.3 (0.80 to 2.24$)$ & 0.250 \\
\hline & Widowed/divorced & $17(6.9)$ & 0.7 (0.42 to 1.26$)$ & 0.416 \\
\hline \multirow[t]{4}{*}{ Education } & None & $15(11.5)$ & 1 & - \\
\hline & Primary & $40(6.4)$ & 0.5 (0.28 to 0.99$)$ & 0.046 \\
\hline & Secondary & $38(11.9)$ & $1.0(0.55$ to 1.97$)$ & 0.899 \\
\hline & Post secondary & $12(16.9)$ & 1.6 (0.69 to 3.58$)$ & 0.280 \\
\hline \multirow[t]{3}{*}{ Employment status } & Unemployed & $35(6.2)$ & 1 & - \\
\hline & Self employed & $58(12.0)$ & 2.0 (1.32 to 3.18$)$ & 0.001 \\
\hline & Employed & $12(12.1)$ & $2.1(1.04$ to 4.16$)$ & 0.038 \\
\hline \multirow[t]{3}{*}{ Asset Groups } & Lowest, Q1 & $38(9.6)$ & 1 & - \\
\hline & Q2 & $39(9.7)$ & 1.0 (0.63 to 1.62$)$ & 0.969 \\
\hline & Highest, Q3 & $28(8.0)$ & 0.8 (0.49 to 1.35$)$ & 0.418 \\
\hline \multirow[t]{3}{*}{ Perceived lack of social support } & No lack: 0 & $1(33.3)$ & 1 & - \\
\hline & Moderate lack: 1-7 & $47(15.0)$ & 0.9 (0.57 to 1.44$)$ & 0.679 \\
\hline & Severe lack: 8+ & $71(8.6)$ & - & - \\
\hline \multirow[t]{3}{*}{ Total Social Group size } & 3 or less & $15(10.4)$ & 1 & - \\
\hline & $4-8$ & $50(9.6)$ & $0.9(0.50$ to 1.69$)$ & 0.780 \\
\hline & 9 or more & $40(8.2)$ & $0.8(0.42$ to 1.46$)$ & 0.436 \\
\hline \multirow[t]{3}{*}{ Life events } & $0-1$ & $36(10.0)$ & 1 & - \\
\hline & $2-3$ & $42(8.8)$ & $0.9(0.55$ to 1.39$)$ & 0.565 \\
\hline & 4 or more & $27(8.7)$ & $0.9(0.51$ to 1.46$)$ & 0.586 \\
\hline \multirow[t]{2}{*}{ Presence of CMD } & No & $96(9.3)$ & 1 & - \\
\hline & Yes & $9(7.6)$ & 0.8 (0.39 to 1.62$)$ & 0.526 \\
\hline \multirow[t]{2}{*}{ Carer for more than $4 \mathrm{~h}^{*}$} & No & $2(7.7)$ & 1 & - \\
\hline & Yes & $13(7.6)$ & $1.0(0.21$ to 4.64$)$ & 0.987 \\
\hline \multirow[t]{2}{*}{ Spent time in institution before age 16} & No & $81(8.8)$ & 1 & - \\
\hline & Yes & $24(10.9)$ & 1.3 (0.78 to 2.05$)$ & 0.333 \\
\hline \multirow[t]{2}{*}{ Did not live continuously with both natural parents until age 16} & No & $93(9.7)$ & 1 & - \\
\hline & Yes & $12(6.8)$ & 0.7 (0.37 to 1.28$)$ & 0.235 \\
\hline
\end{tabular}

Factors significant at the bivariate level included an increased risk of alcohol use in men (OR 0.3, 95 \% C.I. $=0.21$ to $0.53, p<0.001$ for women), those with no education (OR 0.5, $95 \%$ C.I. $=0.28$ to $0.99, p=0.046$ for primary education) and those who are employed (OR
2.1, C.I. $=1.04$ TO $1.35, p=0.038)$ or self-employed (OR 2.0,C.I. $=1.32$ to $3.18, p<0.001$ ).

Forward stepwise regression modelling allowed for adjustment of variables significant at the bivariate level (see Table 3). Current alcohol use remained significantly 
Table 3 Risk factors for current alcohol use using logistic regression analysis (adjusted odds ratios)

\begin{tabular}{llll}
\hline Factors & & Adjusted OR (95 \% C.I) & $p$-value \\
\hline Sex (=female) & & $0.4(0.23$ to 2.75$)$ & $<0.001$ \\
Employment status & Self employed & $1.8(1.13$ to 2.75$)$ & 0.013 \\
& Employed & $1.5(0.73$ to 3.00$)$ & 0.283 \\
\hline
\end{tabular}

higher in men (OR 0.4, C.I. $=0.23$ to $2.75, p<0.001$ for women) and the self-employed (OR 1.8, C.I. $=1.13$ to $2.75, p=0.013)$.

Table 4 shows the relationship of hazardous alcohol use, (audit score of 8 or more), with sociodemographic variables, social variables and CMD. The prevalence of hazardous alcohol use (AUDIT score greater than 8 ) was $6.4 \%$.

Factors significant at the bivariate level included an increased risk of hazardous drinking in men (OR 0.3, C.I. = 0.16 to $0.51, p<0.001$ for women), those with no education (OR 0.5, C.I. $=0.24$ to $1.02, p=0.057$ for those with primary education), those living in large households (OR 2.0 , C.I. $=1.19$ to $3.22, p=0.008$ ), those who are single (OR 1.92.0, C.I. 1.05 to $3.28, p=0.033$ ), and those who are self-employed (OR 2.0, C.I. $=1.22$ to 3.40, $p=0.006$ ) Table 5 .

Table 5 shows the final adjusted model. The risk of hazardous drinking was increased in men (OR 0.3, C.I. $=0.17$ to $0.58 p<0.001$ for women), people living in larger households (OR 1.8, C.I. $=1.09$ to 2.97, $p=0.021$ ), people who were single (OR 1.7,C.I. $=0.92$ to 3.04, $p=0.093$ ), and those who are self-employed (OR 1.8, C.I. $=1.04$ to 2.99, $p=0.036)$.

\section{Discussion}

\section{Overall findings}

This study reports the prevalence of current and life time alcohol use and hazardous drinking in a health and demographic surveillance site in a rural area of Kenya, near Lake Victoria, and found that current alcohol consumption was $9.2 \%$, with lifetime use only marginally higher at $10.8 \%$. The rate of hazardous drinking was $6.4 \%$. Rates were higher in men than in women. Risk factors were further explored for current alcohol consumption and for hazardous drinking. Current alcohol use was significantly higher in men (OR 0.4, $p<0.001$ for women) and in the self-employed (OR 1.8, $p=0.013$ ) in the adjusted analysis. Hazardous drinking was also greatly increased in men (OR $0.3, p<0.001$ for women), in people living in larger households (OR 1.8, $p=0.021$ ), people who were single (OR 1.7, $p=0.093$ ), and those who are self-employed (OR 1.8, $p=0.036$ ). Contrary to expectation, psychosocial variables were not significant risk factors in the adjusted analyses.

\section{Comparison of findings with other relevant studies}

The rates of alcohol consumption and hazardous drinking found in this household study of a rural district in western Kenya are relatively low compared to those found in other household studies of Kenya.

A 1990 cross-sectional survey of 15324 household heads in Kisumu district in Kenya (thus including Kisumu town and the surrounding rural areas including our study area of Maseno, revealed that the reported rate of current alcohol use was $6.4 \%$ [47], while a more recent survey near Kisumu of 72, 292 adults found a past month prevalence of $7.3 \%$ [24], so it looks as if over an intervening quarter century the rate of alcohol use in this area of Kenya has only marginally increased.

In the rest of Kenya, reported rates are higher. Thus the World health Survey data for Kenya found a life time prevalence of alcohol consumption of $26.2 \%$ for rural adults [48], and a national survey In Kenya [22] found a lifetime prevalence rate for alcohol of $39 \%$ and a current prevalence rate of $13 \%$ for people aged between 15 to 64 years. A later subnational survey of 500 households and 3500 adult respondents in Central Province [23] found a lifetime prevalence of $29.6 \%$ (53\% in males and $8 \%$ in females); and a current prevalence of $18 \%$ (34\% in males and $3 \%$ in females).

Studies of school children and college students tend to find still higher rates of alcohol consumption and hazardous drinking. A recent study of alcohol consumption in a sample of Kenyan secondary school students in 2011 found that nearly half (48.9\%) indicated past consumption of alcohol, with one fifth (18.5\%) maintaining usage [49]. Respondents from private schools had the highest proportion of current consumers at $22.9 \%$ ). Alcohol use was higher in males than females, in school grade 4 compared to grade 1 , and was associated with increased sexual activity and violence.

Similarly, another survey of secondary school children, this time in Kisumu town, found that $57.9 \%$ had consumed alcohol at least once in their life time, with rates higher in older age groups and in boys [50], while a much earlier survey of Nairobi school children conducted over 30 years ago found even then that around $10 \%$ of students drank more than three times a week [51]. Since half the population in our study area is aged under 15 , these young people represent a crucial population at future risk of sustained alcohol consumption and hazardous drinking. It is worth noting that in our study the proportion of hazardous drinkers is around two thirds of the men and half of the women who drank at least one unit in the last week, whereas the equivalent proportion in England [27] is half of the men and one third of the women. This may suggest that the trajectory to hazardous drinking is faster in Kenya than in England, and further research is needed to elucidate this. 
Table 4 Prevalence of hazardous alcohol consumption and its relationship with socio demographic variables, social variables and CMD, using unadjusted odds ratios

\begin{tabular}{|c|c|c|c|c|}
\hline \multirow{2}{*}{$\begin{array}{l}\text { Factors } \\
\text { Hazardous alcohol use }\end{array}$} & & Prevalence: n (\%) & Unadjusted OR (95 \% C.I) & $P$ - value \\
\hline & & \multicolumn{2}{|l|}{$73(6.4)$} & \\
\hline \multirow[t]{2}{*}{ Sex } & Male & $57(9.5)$ & 1 & - \\
\hline & Female & $16(2.9)$ & 0.3 (0.16 to 0.51$)$ & $<0.001$ \\
\hline \multirow[t]{3}{*}{ Age group } & $<30$ years & $23(8.2)$ & 1 & - \\
\hline & $30-60$ years & $29(6.5)$ & 0.8 (0.44 to 1.37$)$ & 0.379 \\
\hline & $>60$ years & $10(5.9)$ & 0.7 (0.32 to 1.50$)$ & 0.356 \\
\hline \multirow[t]{2}{*}{ Household size } & $<=6$ people & $25(4.4)$ & 1 & - \\
\hline & $>6$ people & $48(8.3)$ & 2.0 (1.19 to 3.22$)$ & 0.008 \\
\hline \multirow[t]{3}{*}{ Marital Status } & Married/cohabiting & $42(5.9)$ & 1 & - \\
\hline & Single & $19(10.4)$ & 1.9 (1.05 to 3.28$)$ & 0.033 \\
\hline & Widowed/divorced & $12(4.8)$ & $0.8(0.42$ to 1.57$)$ & 0.542 \\
\hline \multirow[t]{4}{*}{ Education } & None & $11(8.4)$ & 1 & - \\
\hline & Primary & $27(4.3)$ & 0.5 (0.24 to 1.02$)$ & 0.057 \\
\hline & Secondary & $28(8.8)$ & $1.0(0.50$ to 2.17$)$ & 0.904 \\
\hline & Post secondary & $7(9.9)$ & $1.2(0.44$ to 3.23$)$ & 0.728 \\
\hline \multirow[t]{3}{*}{ Employment status } & Unemployed & $25(4.4)$ & 1 & - \\
\hline & Self employed & $42(8.7)$ & $2.0(1.22$ to 3.40$)$ & 0.006 \\
\hline & Employed & $6(6.1)$ & $1.4(0.55$ to 3.48$)$ & 0.483 \\
\hline \multirow[t]{3}{*}{ Asset Groups } & Lowest, Q1 & $27(6.9)$ & 1 & - \\
\hline & Q2 & $20(4.1)$ & 0.7 (0.38 to 1.25$)$ & 0.226 \\
\hline & Highest, Q3 & $26(7.4)$ & $1.1(0.61$ to 1.86$)$ & 0.838 \\
\hline \multirow[t]{2}{*}{ Presence of CMD } & No & $65(6.3)$ & 1 & - \\
\hline & Yes & $8(6.7)$ & $1.1(0.50$ to 2.28$)$ & 0.866 \\
\hline \multirow[t]{3}{*}{ Social support group size } & $0-3$ & $6(4.2)$ & 1 & - \\
\hline & $4-8$ & $35(6.7)$ & 1.7 (0.69 to 4.04$)$ & 0.261 \\
\hline & $9+$ & $32(6.7)$ & $1.6(0.67$ to 4.00$)$ & 0.278 \\
\hline \multirow[t]{3}{*}{ Life events } & $0-1$ & $28(7.8)$ & 1 & - \\
\hline & $2-3$ & $28(5.9)$ & 0.7 (0.43 to 1.28$)$ & 0.280 \\
\hline & $4+$ & $28(5.5)$ & 0.7 (0.37 to 1.29$)$ & 0.247 \\
\hline \multirow[t]{4}{*}{ Perceived lack of social support } & No lack: 0 & $0(-)$ & 1 & - \\
\hline & Moderate lack: 1-7 & $24(7.7)$ & 1.3 (0.80 to 2.19$)$ & 0.282 \\
\hline & Severe lack: $8+$ & $49(5.9)$ & - & - \\
\hline & Positive & $14(5.2)$ & 0.7 (0.38 to 1.30$)$ & 0.263 \\
\hline \multirow[t]{2}{*}{ Carer for more than $4 \mathrm{~h}$ a week } & No & $1(3.9)$ & 1 & - \\
\hline & Yes & $9(5.3)$ & $1.4(0.17$ to 11.44$)$ & 0.760 \\
\hline \multirow[t]{2}{*}{ Spending time in institution before age 16} & No & $61(6.6)$ & 1 & - \\
\hline & Yes & $12(5.5)$ & $0.8(0.43$ to 1.54$)$ & 0.523 \\
\hline \multirow[t]{2}{*}{ Not living continuously with both natural parents up to I age 16} & No & $67(7.0)$ & 1 & - \\
\hline & Yes & $6(3.4)$ & $0.5(0.20$ to 1.11$)$ & 0.084 \\
\hline
\end{tabular}

Alcohol consumption is usually found to be higher in people with lower socioeconomic status [52, 53], and indeed a household survey of districts adjacent to our study area of Maseno found that the poorest had significantly higher rates of current alcohol consumption [24]. A study in two urban areas of Tanzania of differing levels of poverty, using similar methodology and instruments to this survey, found that in a random sample of 
Table 5 Risk factors for hazardous drinking using logistic regression analysis (adjusted odds ratios).s.

\begin{tabular}{llll}
\hline Factors & $\begin{array}{l}\text { Adjusted OR } \\
\text { (95\% C.I) }\end{array}$ & $p$-value \\
\hline Sex (=female) & $0.3(0.17$ to 0.58$)$ & $<0.001$ \\
Household size (>6 people) & $1.8(1.09$ to 2.97$)$ & 0.021 \\
Marital Status & Single & $1.7(0.92$ to 3.04$)$ & 0.093 \\
& Widowed/divorced & $1.2(0.57$ to 2.39$)$ & 0.671 \\
Employment status & Self employed & $1.8(1.04$ to 2.99$)$ & 0.036 \\
& Employed & $1.1(0.42$ to 2.74$)$ & 0.892 \\
\hline
\end{tabular}

899 adults aged $15-59$, rates of alcohol consumption were $17.2 \%$. Living in the less affluent area was associated with higher lifetime rates of alcohol use [53]. It is therefore surprising that we did not find an association with socioeconomic status or poverty in this study, although we did with self-employment. We also found a high proportion of abstainers who have never consumed alcohol and this phenomenon has been noted by others in Africa [54].

It is possible that the low rates of current alcohol consumption and of hazardous drinking found in this study result from a combination of the extreme poverty of the area such that it is very hard to pay for alcohol, the widespread religious conservatism of a high proportion of the population, and the potential effectiveness of the recent Kenya Alcoholic Drinks Control Act 2010, which is intended to control production, limit outlets, and control consumption and age of use [23]. In an area characterised by chronic poverty and disease, religion thrives giving hope to people struggling with a relatively harsh existence. We did not enquire about religious affiliation in our study but Maseno area has a relatively high proportion of conservative Protestant based Christian groups who are very strict about banning alcohol consumption e.g. Seventh Day Adventists and Legio Maria. The proximity of our study area to Kisumu town means that law enforcement against illegal brews is stricter than in more remote rural areas. Further studies are needed to clarify these possible influences.

Relationships between psychosocial variables such as life events and social supports and alcohol use and hazardous drinking are variable in the literature [57]. Studies in western countries have found that life events contribute to problem drinking while social support can buffer its effects [58], although the buffering effect of social support disappears in poor populations [59]. Relationships of alcohol with CMD are also variable. For example, the British national psychiatric morbidity survey did not find a relationship between alcohol dependence and CMD [27], but a relationship between hazardous drinking and CMD was found in Tanzania [53].

\section{Strengths of study}

The strengths of the study are the use of a health and demographic surveillance site for the random sample of households, the high response rate, and the systematic approach to the clinical and sociodemographic assessments. The population in the surveillance site is regularly monitored by field staff who visit each household bi-annually to capture health and demographic information (Birth rates, Death rates, Causes of Death, Pregnancies, Immunization status, in-and out-migrations). Various studies nested on the DSS platform take advantage of the sampling frame inherent in the HDSS, whether at individual, household/ compound or regional levels. This familiarity with survey procedures is likely to have been influential in the achievement of a high response rate.

\section{Limitations of study}

As always, the potential for measurement error when using screening instruments should be acknowledged, given self-reported experiences may be subject to recall or social desirability or cultural response bias [55]. In addition, the measurement of alcohol units in Africa is difficult because of the ubiquity of relatively strong home brews [56] hence some bias due to measurement error may exist.

The implementation of the study was hampered by a number of logistical challenges which included the difficult terrain, posing problems for local transport for research staff, and continuing administrative difficulties, which led to delays in the implementation of the project. The interviewing period, initially planned to last 3 months, took place over a period of 6 months, and was temporarily halted for several weeks over the period of the 2013 election due to further fears of election unrest.

\section{Conclusion}

The rates of current alcohol use and hazardous drinking found in this study of a poor rural area in Kenya remain relatively low, and represent an important public health prevention and educational opportunity to keep such rates low in this area before increasing income and employment opportunities enable higher access to alcohol, and higher rates of consumption with its associated health hazards, and before the higher consumption found by other studies in urban youth, especially neighbouring Kisumu town, spreads to the rural areas. We recommend that school health programmes and adult public health education strategies include information about the harmful effects of alcohol use and hazardous drinking, that access to cheap illegal brews continues to be restricted, that pricing policies of legal brews do not encourage cheaper availability of alcohol, that primary care staff are trained in early detection and prompt management of moderate and severe levels of alcohol consumption and hazardous drinking 
with its associated suicidal risk and physical comorbidity, as well as advice to those who drink regularly at low levels. We recommend that further research is conducted to elucidate the relationship between alcohol consumption, hazardous drinking and psychosocial variables.

\section{Abbreviations}

CIS-R: Clinical interview schedule revised; CMD: Common mental disorders; PSQ: Psychosis screening questionnaire; AUDIT: Alcohol use disorders identification test; KCL: Kings College London; KEMRI: Kenya Medical Research Institute; KWHDSS: Kombewa West Health and Demographic Surveillance Site.

\section{Competing interests}

The authors declare that they have no competing interests.

\section{Authors' contributions}

$R \mathrm{~J}$ conceived the study and had overall responsibility for the project; RJ, DK, $\mathrm{BO}$ and $\mathrm{CO}$ designed the study; JKM coordinated the project management in Kenya; PS drew the sample within Kombewa DHSS; BO, CO and latterly LO provided local field supervision; $\mathrm{RO}$ analysed the data, RJ wrote the first draft of the paper, all authors commented on successive drafts, interpretation of results and approved the final version.

\section{Acknowledgements}

We are grateful to the UK Department for International Development for funding the research reported here. We are also grateful to the Nuffield Foundation for a timely travel grant to enable LO to visit Kisumu to assist the later stages of the project, to the KWDHSS for access to the health and demographic surveillance site, to Howard Meltzer for designing the sampling procedure, before his untimely death in 2012, to the research assistants and field managers, and last but not least to the people who willingly gave their time to participate in the study.

\section{Author details}

'Health Services and Population Research Department, Institute of Psychiatry, Kings College London, de Crespigny Park, London SE 5 8AF, UK. ${ }^{2}$ Department of Psychiatry, University of Nairobi, Nairobi, Kenya. ${ }^{3}$ Kenya Medical Research Institute, Nairobi, Kenya. ${ }^{4}$ Ministry of Health, Nairobi, Kenya. ${ }^{5}$ Kombewa Health and Demographic Surveillance Site, Kombewa, Kenya.

${ }^{6}$ Kenya Medical Training College, Nairobi, Kenya.

\section{Received: 9 February 2015 Accepted: 10 September 2015}

\section{Published online: 25 September 2015}

\section{References}

1. Yach D. Globalisation and health: exploring the opportunities and constraints for health arising from globalisation. Globalisation and Health. 2005;1:1-2.

2. Ezzati M, Lopez AD, Rodgers A, Murray CJ. Comparative Quantification of Health Risks. Global and Regional Burden of Disease Attributable to Selected Major Risk Factors. Geneva, Switzerland: World Health Organization; 2004

3. Rehm J, Taylor B, Room R. Global burden of disease from alcohol, illicit drugs and tobacco. Drug Alcohol Rev. 2006;25:503-13.

4. Corrao G, Bagnardi V, Zambon A, La Vecchia C. A meta analysis of alcohol consumption and the risk of 15 diseases. Prev Med. 2004;38:613-9.

5. Lau K, Freyer-Adam J, Coder B. Dose response relation between volume of drinking and alcohol related diseases in male general hospital inpatients. Alcohol Alcohol. 2008:443:34-8.

6. Grant B. Prevalence and correlates of alcohol use and DSM-IV alcohol dependence in the United States: results of the National Longitudinal Alcohol Epidemiology survey. J Stud Alcohol Drug. 1997;58:464-73.

7. van Oers J, Bongers I, van de Goor L, Garretsen H. Alcohol consumption, alcohol-related problems, problem drinking, and socioeconomic status. Alcohol Alcoholism. 1999;34:78-88.

8. Room R, Jernigan D, Carlini-Marlatt B, Gureje O, Mäkelä K, Marshall M et al. Alcohol in Developing Societies: A Public Health Approach. Vol. 46. Helsinki, Finland: Finnish Foundation for Alcohol Studies in collaboration with The World Health Organization; 2002.

9. World Health Organisation. Global Status Report on Alcohol. Geneva, Switzerland: World Health Organisation; 2004.
10. Klatsky AL, Udaltsova N. Alcohol Drinking and Total Mortality Risk. Ann Epidemiol Review. 2007;17(suppl):S63-S67

11. Lee SJ, Sudore RL, Williams BA, Lindquist K, Chen HL, Covinsky KE, Functional limitations, socioeconomic status, and all cause mortality on moderate alcohol drinkers. J Am Geriatric Soc. 2009;57:955-962.

12. Arriola L, Martinez-Camblor P, Lrranag N, Basterretxea M, Amiano P, MorenoIribas $C$ et al. Alcohol intake and the risk of coronary heart disease in the Spanish EPIC cohort study. Heart. 2010:96:124-130.

13. Hansel B, Thomas F, Pannier B, Bean K, Kontush A, Chapman MJ, et al. Relationship between alcohol intake, health and social status and cardiovascular risk factors in the urban Paris-lle-De-France Cohort: is the cardioprotective action of alcohol a myth? Eur J Clin Nutr. 2010;64(6):561-8.

14. Joshi P, Islam S, Pais P, Reddy S, Dorairaj P, Kazmi K, et al. Risk Factors for early Myocardial Infarction in South Asians compared with individuals in other countries. JAMA. 2007;297:286-94.

15. Roy A, Prabhakaran D, Jeemon P, THankappan KR, Mohan V, RamakrishnanL et al. Impact of alcohol on coronary heart disease in Indian men. Atherosclerosis. 2010;210:531-535.

16. Acuda W, Othieno CJ, Obondo AA, Chrome IB. The Epidemiology of Addictions in Sub-Saharan Africa: A Synthesis of Reports, Reviews, and Original articles. Am J Addict. 2011;20(2):87-99.

17. Kinoti KE, Jason LA, Harper GW. Determinants of alcohol, khat and bhang use in rural Kenya. African Journal of Drug and Alcohol Studies. 2013;10(2):107-18.

18. Rapid Situation Assessment Of The Status Of Drug And Substance Abuse In Kenya, 2012

19. World Health Organisation. Global Strategy to Reduce the Harmful Use of Alcohol. Geneva: World Health Organisation; 2010.

20. Ndetei DM, Khasakhala LI, Ongecha-Owuor FA, Kuria MW, Mutiso V, Kokoya DA. Prevalence of substance abuse among patients in general medical facilities in Kenya. Subst Abus. 2009:30:182-90.

21. Othieno C, Kathuku D, Ndetei D. Substance abuse in outpatients attending rural and urban health centres in Kenya. East Afr Med J. 2009;77:592-5.

22. NACADA (National Authority for the Campaign against Alcohol and Drug Abuse). Rapid situation assessment of drug and substance abuse in Kenya. Nairobi: NACADA; 2007.

23. NACADA. Alcohol use in Central Province of Kenya. A baseline survey on magnitude, causes and effects from the perspective of community members and individuals. 2011.

24. Lo TQ, Oeltmann JE, Odhiambo FO, Beynon C, Pevzner E, Cain KP, et al. Alcohol Use, drunkenness and tobacco smoking in rural western Kenya. Trop Med Int Health. 2013;18:506-15.

25. Sifuna P, Oyugi M, Ogutu B, Andagalu B, Otieno A, Owira V, et al. Health \& Demographic Surveillance System Profile: The Kombewa Health and Demographic Surveillance System (Kombewa HDSS). Int J of Epid, 2014. doi:10.1093/ije/dyu139.

26. Kish L. A procedure for objective respondent selection within households. J Am Stat Assoc. 1949:46:380-7.

27. Health and Social Care Centre. Adult Psychiatric Morbidity Survey 2007. A household survey. 2009. http://www.hscic.gov.uk/pubs/psychiatricmorbidity07. Accessed 14.9.15

28. Lewis G, Pelosi A, Araya RC, Dunn G. Measuring psychiatric disorder in the community: a standardised assessment for use by lay interviewers. Psychol Med. 1992;22:465-89.

29. Saunders JB, Aasland OG, Babor TF, de la Fuente JR, Grant M. Development of the alcohol use disorders identification test (AUDIT): WHO collaborative project on early detection of persons with harmful alcohol consumption II. Addiction. 1993:88:791-804.

30. Patel V, Kirkwood BR, Pednekar S, Weiss H, Mabey D. Risk factors for common mental disorders in women: population-based longitudinal study. Brit J Psychiat. 2006;189:547-55

31. Wickramasinghe SC, Rajapakse L, Abeysinghe R, Prince M. The clinical interview schedule-sinhala version: validation in a community setting in Sri Lanka. Int J Method Psychiatr Res. 2002;11:169-77.

32. Araya R, Rojas G, Aritsch R, Acuna J, Lewis G. Common mental disorders in Santiago, Chile: prevalence and socio-demographic correlates. Brit J Psychiat. 2001;178:228-33.

33. Jenkins R, Njenga F, Okonji M, Kigamwa P, Baraza M, Ayuyo J, et al. Prevalence of common mental disorders in a rural district of Kenya, and socio-demographic risk factors. Int J Environ Res Public Health. 2012;9:1810-9. do::10.3390/ijerph9051810. 
34. Ngoma MC, Prince M, Mann A. Common mental disorders among those attending primary health clinics and traditional healers in urban Tanzania. Brit J Psychiat. 2003;183:349-55

35. Jenkins R, Mbatia J, Singleton N, White B. Common mental disorders and risk factors in urban Tanzania. Int J Environ Res and Pub Health. 2010;7(6):2543-58

36. World Health Organisation. The ICD-10 Classification of Mental and Behavioural Disorders. Clinical descriptions and diagnostic guidelines. 1st ed. Geneva, Switzerland: World Health Organisation; 1992.

37. Jenkins $R$, Bebbington $P$, Brugha $T$, Farrell M, Gill $B$, Lewis $G$, et al. The National Psychiatric Morbidity Surveys of Great Britain-Strategy and methods. Psychol Med. 1997;27:765-74.

38. Jenkins R, Lewis $G$, Bebbington P, Brugha T, Farrell M, Gill B, et al. The National Psychiatric Morbidity Surveys of Great Britain - Initial Findings from the Household Survey. Psychol Med. 1997;27:775-90.

39. Breeze E, Maidment A, Bennett N, Flatley J, Carey S. Health Survey for England 1992. London, UK: HMSO; 1994.

40. Meltzer H, Gill B, Petticrew M, Hinds K. OPCS Survey of Psychiatric Morbidity: Report 1.The Prevalence of Psychiatric Morbidity among Adults Ages 16-64 Living in Private Households in Great Britain. London, UK: HMSO; 1995

41. Singleton N, Bumpstead R, O'Brien M, Lee A, Meltzer H. Psychiatric Morbidity among Adults Living in Private Households, 2000. London, UK: TSO; 2001.

42. Brugha T, Bebbington PE, MacCarthy B, Potter J, Sturt E, Wykes T. Social networks, social support and the type of depressive illness. Acta Psychiatr Scand. 1987;76:664-73.

43. Brugha T, Wing J, Brewin C, MacCarthy B, Lesage A. The relationship of social network deficits with deficits in social functioning in long-term psychiatric disorders. Soc Psychiatry Psychiatr Epidemiol. 1993;28:218-24.

44. Statacorp. Stata Statistical Software: Release 11.2. College Station TX: StataCorp LP; 2003.

45. Moser $\mathrm{C}$. The asset vulnerability framework: Reassessing urban poverty reduction strategies. World Dev. 1998;26(1):1-19.

46. Morris SS, Carletto C. Validity of rapid estimates of household wealth and income for health surveys in rural Africa. J Epidemiol Community Health. 2000;54:381-7.

47. Some ES. Misuse of drugs: perceptions of household heads in Kisumu district, Kenya. East Afr Med J. 1994;71(2):93-7.

48. World Health Organization. Global status report on alcohol and health. Geneva: World Health Organization; 2011.

49. Ndetei DM, Khasaklala LI, Mutiso V, Ongecha Owuor FA, Kokonya DA. Patterns of Drug Abuse in Public Secondary Schools in Kenya. Subst Abus. 2009;30:69-78.

50. Otieno AO, Ofulla AVO. Drug abuse in Kisumu town western Kenya. Afr J Food, Agric, Nutr Dev. 2009;9:846-858

51. Kwamanga DHO, Odhiambo JA, Emukoye El. Prevalence and risk factors of smoking among secondary school students in Nairobi. EAMJ. 2003;80:207-12.

52. Dohrenwend BP, Levav I, Shrout PE, Schwartz S, Naveh G, Link BG, et al. Socioeconomicstatus and psychiatric disorders : the causation-selection issue. Science. 1992;255:946-52.

53. Mbatia J, Jenkins R, Singleton N, White B. Prevalence of Alcohol Consumption and Hazardous Drinking, Tobacco and Drug Use in Urban Tanzania, and Their Associated Risk Factors. Int J Environ Res Public Health. 2009;6:1991-2006. doi:10.3390/ijerph6071991.

54. Clausen T, Rossow I, Naidoo N, Kowal P. Diverse alcohol drinking patterns in 20 African countries. Addiction. 2009;104:1147-54.

55. World Health Organisation. Global status report on alcohol and health. Geneva: World Health Organisation; 2011.

56. Papas RK, Sidle JE, Wamalwa ES, Okumu TO, Bryant KL, Goulet JL, et al. Department of Medicine, Yale University School of Medicine, New Haven, $C T$, USA Estimating Alcohol Content of Traditional Brew in Western Kenya Using Culturally Relevant Methods: The Case for Cost Over Volume. AIDS Behav. 2010;14(4):836-44. doi:10.1007/s10461-008-9492-z.

57. Veenstra MY, Lemmens PH, Friesema IH, Garretsen HE, Knotterus JA, Zwietering PJ. A literature overview of the relationship between life events and alcohol use in the general population. Alcohol Alcohol. 2006:41:455-63.
58. Johnson KA, Jennison KM. Stressful loss and the buffering effect of social support on drinking behaviour among African Americans: results of a national survey. J Alcohol Drug education. 1994;39:1-24.

59. Mulia N, Schmidt L, Bond J, Jacobs L, Korcha R. Stress, Social Support and Problem Drinking among Women in Poverty. Addiction. 2008;103:1283-93.

\section{Submit your next manuscript to BioMed Central and take full advantage of:}

- Convenient online submission

- Thorough peer review

- No space constraints or color figure charges

- Immediate publication on acceptance

- Inclusion in PubMed, CAS, Scopus and Google Scholar

- Research which is freely available for redistribution 